\title{
ABSOLUTISMO, TIRANÍA Y RESISTENCIA CIVIL EN EL PENSAMIENTO POLÍTICO DE JOHN LOCKE
}

\author{
Óscar Godoy Arcaya
}

Durante el año en curso se han realizado en el país distintas actividades de rememoración de la obra de John Locke (1632-1704), con ocasión del tercer centenario de su muerte. En este ensayo, Óscar Godoy nos propone un estudio sobre las ideas de Locke acerca el absolutismo, la tiranía y la resistencia civil. Estas ideas se contextualizan en el tiempo político de la Inglaterra de la revolución de 1688 y en el debate intelectual sobre el origen de la comunidad política y la libertad natural y política de la persona humana. Pero, a la vez, de su exposición fluye una concepción de las libertades y derechos políticos "duros" y del Estado liberal, que siguen vigentes en la actualidad. El derecho de resistencia, como un derecho inalienable de la persona humana, vinculado al derecho a la legítima defensa, aparece en este ensayo como un elemento fundamental del discurso lockeano.

Óscar Godoy Arcaya. Doctor en Filosofía, Universidad Complutense de Madrid. Profesor titular de Teoría Política del Instituto de Ciencia Política de la Pontificia Universidad Católica de Chile y profesor del Institut des Études Politiques de París. Miembro de número de la Academia de Ciencias Sociales, Políticas y Morales del Instituto de Chile. Consejero del Centro de Estudios Públicos. 


\section{E}

1 pensamiento político maduro de John Locke (1632-1704), tal como aparece expuesto en los Dos Tratados sobre el Gobierno (1689), publicados en el último tercio de su vida, es el resultado de un largo proceso de elaboración. En el mismo año 1689 se publica también su famosa Carta sobre la Tolerancia, y al siguiente, en 1690 su capital Ensayo sobre el Entendimiento Humano. En un breve espacio de tiempo, ven la luz sus principales obras, aquellas que le aseguraron posterioridad tanto en la filosofía como en el pensamiento político. La acumulación de estas publicaciones, en la fase final de su vida, permite atribuirles el carácter de exponentes del "pensamiento maduro" de Locke, y, así, fijar y delimitar con facilidad el campo de este trabajo.

Este ensayo tiene dos propósitos. En primer término, analizar las principales ideas sobre la monarquía absoluta de derecho divino, que son objeto de la refutación de Locke. En segundo lugar, hacer un trazado de los principales argumentos de Locke acerca del último recurso de que dispone la sociedad civil, o sea, la resistencia civil, contra todas las formas de sujeción política que violen los límites de la libertad natural del hombre. La cuestión del absolutismo, el "mal francés" (morbo gallico), como lo llamaban los ingleses de la época, es discutido por Locke en el contexto de un tema tradicional de la teoría política antigua y medieval, que es la tiranía como adversaria e incompatible con el gobierno civil de poderes limitados. A su vez, la resistencia civil de Locke evoca fuertemente la discusión medieval sobre la legitimidad de la desobediencia, el clamor al cielo y la rebelión contra el tirano. No obstante, creo que este ensayo expone la innovación lockeana, que imprime a sus concepciones una fuerza inédita y las pone en la primera línea del pensamiento político moderno. Para cumplir con estos propósitos he dividido el texto en dos partes. La primera —dedicada al absolutismo- está subdividida en tres secciones: (1) breve reseña de la coyuntura política en que la obra política madura de Locke recibe un impulso decisivo; (2) esquema de las teorías políticas vigentes en la época, para situar el pensamiento de Locke en su contexto intelectual; (3) exposición de los argumentos centrales de la teoría absolutista más radical de la época. En la segunda parte, se desarrolla la teoría de Locke sobre la tiranía y la resistencia civil.

\section{La monarquía absoluta de derecho divino, contexto político inglés, la discusión intelectual y los argumentos absolutistas radicales}

La vida de Locke, en los años ochenta de su siglo, es difícil y agitada. Los hechos que anuncian el desenlace revolucionario de 1688, 
actúan sobre su espíritu en forma decisiva, pues precipitan la redacción de sus Dos Ensayos sobre el Gobierno. Por esta razón es conveniente tener una idea acerca de cómo se desarrolla este importante episodio de la historia inglesa. Por otra parte, y en forma paralela, el debate de las ideas sigue su propio curso. Este debate discurre a través de una compleja trama de tendencias y autores, que interactúan entre ellos y se influencian mutuamente. De algún modo, es necesario dar cuenta, aunque sea en forma sumaria, de este asunto. A estos efectos, dedico una sección de este capítulo al tema. Por último, en la tercera sección, se hace una revisión de la teoría sobre la monarquía adánica de derecho divino, cuyo autor es Robert Filmer, no solamente porque es la más radical y sorprendente, sino porque es objeto de la dedicación polémica de Locke en su Primer Ensayo sobre el Gobierno.

\section{Locke y la coyuntura política inglesa de la Exclusión}

La vida de Locke transcurre en el siglo XVII, una de las épocas más tormentosas y agitadas de la historia de Europa y de Inglaterra ${ }^{1}$. Para Locke la controversia sobre el absolutismo tiene un antagonista principal, que es Robert Filmer (1588-1653), autor de una obra que lleva el sugestivo título del Patriarca o el Poder Natural de los Reyes (1680). Durante el período que se extiende entre el nacimiento de Filmer (1588) y la muerte de Locke (1704), Inglaterra experimenta grandes cambios políticos, provocados por las luchas religiosas y los conflictos entre la monarquía de los Estuardo y el Parlamento. Filmer asiste a la querella religiosa entre anglicanos, protestantes y católicos y al proceso de crisis que antecede la caída de la monarquía, que culminó con el dramático juicio, condena y ejecución del rey Carlos I (1649) y a la instauración de la Commonwealth (república) bajo el protectorado de Oliver Cromwell. Locke no solamente asistió a esos acontecimientos, sino que fue testigo del fin del régimen de Cromwe11, la restauración de los Estuardo y, en fin, la "Glorius Revolution" (1688), que terminó con el corto reinado de Jacobo II (1685-1688), e instauró a Guillermo de Orange en el trono de Inglaterra, como rey de una monarquía moderada por la supremacía del poder legislativo. Con el fin de la monarquía de los Estuardo se extinguió cualquier proyecto, real o imaginario, de imponer un régimen absolutista en Inglaterra, mientras en el continente ocurría exactamente lo contrario. En Francia, durante el mismo período, la

${ }^{1}$ La información histórica proviene de Cranston, Maurice: John Locke: A Biography, 1985; Milton, J. R.: Locke's Life and Times, 1994, pp. 5-26; Dunn, John: The Political Thought of John Locke, 1969. 
monarquía absolutista alcanzaba su cenit bajo el extenso reinado de Luis XIV (1638-1715), durante cuyo gobierno, el régimen de derecho divino recibió el apoyo de importantes figuras intelectuales, tales como Jacques Bénigne Bossuet (1627-1704), que no solamente sustentaron el orden político existente, sino que dieron forma al discurso de la monarquía absolutista que Locke refuta en su obra.

La vida de Locke, hasta la restauración monárquica, transcurrió bastante alejada de los asuntos políticos, a los cuales no parece haberles prestado mucha atención. Sus biógrafos nos relatan que entre su ingreso al Christ Church (1652), de Oxford, donde hizo sus estudios de bachillerato y licenciatura, y hasta la muerte de Cromwell (1658), que trajo consigo la Restauración monárquica, con el acceso al trono de Carlos II (1660-1685), no hay evidencias de sus preocupaciones políticas, salvo el hecho de que provenía de una familia puritana, parlamentarista y crítica de la monarquía absoluta. Locke acogió favorablemente el retorno de Inglaterra a la monarquía y a su legitimidad dinástica. Tanto es así, que en 1660 escribió su primer texto político; en efecto, publicó un opúsculo a favor del poder legítimo del magistrado civil para establecer e imponer una forma de culto religioso a la comunidad ${ }^{2}$. Además en 1662 publicó dos trabajos conocidos como Two Tracts on Government, donde Locke sostiene posiciones que rectificará profundamente en su obra madura, tal como la tesis de que el pueblo constituido como cuerpo político debe alienar totalmente sus derechos al soberano o bien la doctrina de la intervención del magistrado en el culto religioso, recién mencionada ${ }^{3}$.

La escritura de estos primeros textos políticos, cuando Locke está en sus treinta años, dan la impresión de un paréntesis en sus preocupaciones principales, que son sus estudios de medicina y química. Pero, en esa misma década de los sesenta, un hecho fortuito marcó un giro en su vida. En efecto, a raíz de una estadía en Oxford, John Ashley Cooper, posteriormente Conde de Shaftesbury, conoce a Locke y entabla una amistad con él que los unirá de por vida. Shaftesbury tuvo una destacada vida pública en la época, y en la década de los setenta alcanzó la alta dignidad de Lord Chancellor del reino. A fines de la misma década, después de romper con el rey Carlos II, Shaftesbury se transforma en el líder del partido Whig, y, por lo mismo, en uno de los principales opositores a la monarquía de los Estuardo. Shaftesbury, poco después de conocer a Locke, lo invitó a inte-

${ }^{2}$ Locke, John: Le Magistrat Civil (An Magistratus Civilis posi res adphoras in divini cultus ritus asciescere, eosque populo imponere? Afirmo), René Fréreux, editor, 1984. Este texto fue incorporado posteriormente (1662) en los Two Tracts on Government, como Second Tract on Government.

${ }^{3}$ Locke, John: Two Tracts on Government, Phillip Abrams, editor, 1967. 
grarse a su servicio, como su médico y asesor. Esta relación fue determinante en la vida de Locke y no es aventurado sostener que precipitó su participación al sector whig y a su militancia activa contra el absolutismo.

Durante los años ochenta del siglo, la conversión al catolicismo de Jacobo Estuardo, duque de York, hermano y heredero del rey Carlos II, puso en la agenda política inglesa la cuestión llamada de la Exclusión. El duque de York se había convertido al catolicismo; en consecuencia su eventual ascenso al trono abrió un escenario plagado de interrogantes, suscitadas por las especulaciones acerca de la futura conducta del rey, principalmente en relación a su presunto designio de restaurar la hegemonía de la Iglesia Católica romana en Inglaterra. Y, enseguida, por el peligro de que el futuro rey siguiera el modelo absolutista francés, sospecha que estaba potenciada por las relaciones del heredero con la monarquía y la persona de Luis XIV.

En el año 1679, Shaftesbury disfrutaba de un gran prestigio y ascendiente político, pues había propuesto y hecho aprobar en el parlamento el Habeas Corpus Act, que consagró constitucionalmente las libertades anglicanas. En la práctica, su activa oposición a las tendencias absolutistas del rey lo condujo a consolidar su liderazgo whig. Ese mismo año, su posición de confrontación con la monarquía de Carlos II sube de tono, pues encabeza la presentación de tres proyectos sucesivos de ley (1679, 1680 y 1691) para cerrar el acceso al trono del duque de York. Las tres iniciativas parlamentarias fracasaron por la eficacia de la acción del rey y del partido de la corte (Tory) para vetarlas. El proceso parlamentario de exclusión tuvo el fuerte apoyo de prominentes figuras intelectuales, entre las cuales se destacaron John Locke, James Tyrrel y Algernon Sydney. Hay evidencias de que Locke, en esos años, estaba componiendo los textos que posteriormente recibirían el título de Dos Tratados sobre el Gobierno ${ }^{4}$. Tyrrel, amigo de Locke, por su parte, publica justamente en 1681 su obra Patriarca non Monarcha, dirigida contra Filmer. Y Sydney, uno de los representantes más importantes del republicanismo inglés de la época, daba inicio a su obra Discourses Concerning Government (publicada póstumamente en 1698) inducido por el impacto que produjo la lectura del Patriarca de Filmer, cuando apareció en 1680. En efecto, durante este álgido período, la publicación póstuma del libro de Robert Filmer levantó una fuerte polémica. La obra tuvo una clamorosa recepción, amplificada por los partidarios

${ }^{4}$ Existe una disputa acerca de la fecha del inicio de la elaboración de esta obra. Peter Laslett, en su edición crítica de los Two Treatises on Government, 1967, sostiene que fue durante la crisis de la Exclusión, una vez que apareció la primera edición del Patriarca (1680) de Filmer. En cambio, Richard Ashcraft, en Revolutionary Politics and Locke's Two Treatises of Government, 1986, afirma que aquello ocurrió en 1679. 
de la monarquía absolutista. De este modo, la figura y la obra de Filmer se entrecruza con la coyuntura política y la discusión sobre la legitimidad de la sucesión monárquica, y, su efecto, en el campo intelectual, es el surgimiento de un movimiento de crítica a la doctrina de la monarquía de derecho divino y de difusión del contractualismo.

Locke no podía estar ajeno a esa circunstancia. Él sostiene en el Primer Tratado sobre el Gobierno que no le habría prestado tanta atención al libro de Robert Filmer, como para refutarlo sistemáticamente, si no hubiese mediado la especial circunstancia de que su texto fuese adoptado como el catecismo del absolutismo. Irónicamente dice así: "lo tomé en mis manos con toda expectación, lo leí con toda la atención debida a un tratado que hizo tanto ruido a su aparición, y no pude menos de confesarme grandemente sorprendido que en un libro que pretende suministrar cadenas para toda la humanidad no se pueda encontrar sino una soga de arena"5.

El fracaso de la vía legal para detener el ascenso de Jacobo Estuardo abrió un segundo escenario. En esta fase interviene otro factor, que estaba operando desde larga data. La oposición a Jacobo Estuardo se había acercado al duque de Monmouth, hijo ilegítimo del Carlos II, para apoyar su pretensión al trono. Monmouth había recibido grandes muestras de predilección por parte de Carlos II, pero cuando éste se dio cuenta de sus aspiraciones hizo una declaración oficial y solemne para establecer la inviolabilidad de la línea de sucesión, que hacía recaer el trono en su hermano Jacobo. Monmouth no aceptó esta decisión de su padre y participó en la conspiración llamada "Rye House plot", que contemplaba el asesinato del rey y su hermano. La conspiración fracasó y Monmouth fue apresado y enviado al exilio poco después que se iniciara la represión real (21 de junio de 1683). En cambio, los cabecillas de la sedición y sus principales partícipes, entre los cuales se incluyó a Algernon Sydney, fueron condenados a muerte y ejecutados. Con algunos meses de anterioridad al desmantelamiento del complot, Shaftesbury, asediado por los servicios judiciales y policiales del rey, había abandonado Inglaterra. Asilado en Holanda, no tardó en morir. Locke, por su parte, salió al exilio dos semanas antes del operativo real contra los conspiradores ${ }^{6}$. Mientras en Inglaterra se desarrollaban los juicios contra los conspiradores, el gobierno de Carlos II demandó al gobierno holandés la detención y extradición de Locke, razón por la cual éste se sumergió en el anonimato. Carlos II no volvió a convocar al Parlamento durante el resto de su reinado.

${ }^{5}$ Locke, John: Primer Tratado sobre el Gobierno, Instituto de Estudios Políticos, 1966, Libro I, Cap. 1, p. 100. Rotterdam.

${ }^{6}$ No se sabe cómo logró salir de Inglaterra, pero en septiembre de 1683 está en 
Carlos II murió en febrero de 1685. El duque de York ascendió al trono como Jacobo II. Monmouth, exiliado en Europa continental, cruzó el Canal de la Mancha en junio del mismo año, acompañado de un séquito de partidarios suyos, con el propósito de deponer al nuevo rey y asumir la sucesión de Carlos II. Tras una corta campaña su expedición fue derrotada. Después de su captura, fue condenado a muerte y ejecutado en la Torre de Londres. No obstante, tres años más tarde, Jacobo II abandonaba el trono, después de enajenarse el apoyo de importantes sectores afectos a la legitimidad de la corona, dejándolo a disposición de Guillermo de Orange. Así concluyó el capítulo final de la revolución inglesa. Unos meses después de este acontecimiento, Locke retornó a Inglaterra.

Una visión esquemática de las tendencias de la teoría política de la época

Es difícil dar una descripción breve y comprehensiva de las distintas corrientes intelectuales vigentes en este período. Sin embargo, he encontrado facilitado este trabajo gracias a James Tully, a quien debo el esquema general de esta sección, aunque no todo su contenido, por las naturales discrepancias que derivan de diferentes interpretaciones de los autores. Tully organiza un mapa de los movimientos intelectuales que en la época de Locke se hacen cargo de la cuestión de la libertad natural del hombre y los orígenes del poder político. Sobre la base de dos grandes tendencias, el voluntarismo y el intelectualismo ${ }^{7}$, clasifica las principales corrientes intelectuales que asumen esa tarea. La figura original de la primera tendencia es Guillermo de Occam, que en el siglo XIV expuso una teoría acerca de la libertad natural del hombre y de su poder de hacer lo que su voluntad quiere, como fundamento de la moral y la política. Esta tendencia, a su vez, en los siglos XVI y XVII se diversificó en tres escuelas: el conciliarismo, el individualismo radical y el absolutismo.

El conciliarismo sostiene que siendo el ser humano libre por naturaleza, la soberanía reside en "los hombres organizados" como pueblo. La universitas civium, por ejemplo, que postula Marsilio de Padua, es la comunidad de los ciudadanos, sobre la cual recae el poder soberano de legislar y de atribuir el poder ejecutivo ${ }^{8}$. La comunidad de los hombres libres, como un todo, delega el ejercicio del poder soberano, bajo la condición de que su titular, un individuo o una asamblea, gobierne para el bien común.

${ }^{7}$ Tully, James: Approach to Political Philosophy: Locke in Contexts, 1993, pp. 284-

${ }^{8}$ Marsilio de Padua: El Defensor de la Paz, I, 12, 4-8, en Godoy, Óscar, "Antología del Defensor de la Paz de Marsilio de Padua”, 2003, pp. 381-383. 
El ejercicio de este poder, si no se cumple esta condición esencial, revierte a la universitas civium para la constitución de un nuevo gobierno. La tesis conciliarista no admite otra forma de régimen que no sea el gobierno moderado. Junto con Occam se cita a Jean Gerson, Jacques Almain y John Mair como representantes de esta corriente. Según Tully, el voluntarismo radical individualista sostiene que cada individuo deposita en el gobierno el poder que le otorga la naturaleza de preservar su vida ${ }^{9}$. Obviamente el fin de esta delegación es la organización de un cuerpo político gobernado para realizar el bien común. La violación del fin del gobierno legitima la acción violenta de cualquier individuo para defenestrar o asesinar al gobernante tiránico que haya incurrido en esa conducta. Tully piensa en el humanista cristiano Juan de Mariana como ejemplo de esta posición extre$\mathrm{ma}^{10}$. Una tercera forma de voluntarismo asume la forma de absolutismo. Los poderes de esta forma de régimen monárquico, para sus sostenedores, se originan en la libertad natural absoluta de los individuos. Éstos al abandonar del estado de naturaleza, para organizarse políticamente, no delegan sino que alienan por consentimiento su poder soberano de gobierno de sí mismos, para constituir un régimen político a su vez absoluto. Estimo que Hobbes se ubica en esta corriente voluntarista. Para este autor, una vez que los individuos pactan entre sí, el soberano de los cuales ellos son autores es una persona representativa, investida de un poder político inalienable e indivisible que le autoriza a "utilizar la fortaleza y medios de todos, como lo juzgue oportuno, para asegurar la paz y defensa común"11 (el destacado es mío). Dado que el soberano —un individuo o una asamblea- es un "actor" autorizado por los individuos, que son sus autores, sus actos y palabras son los actos y las palabras de los autores, o sea de los individuos. Este argumento absolutiza al soberano, porque le concede derechos de sujeción total sobre los gobernados, que no pueden contradecir, objetar o juzgar al soberano, pues al hacerlo se contradicen, objetan y juzgan a sí mismos. En el libro II del Leviatán, capítulos 18 y 21, se pueden contrastar los derechos del soberano con las libertades de los sujetos, y concluir que sea cual fuere el régimen político, para Hobbes el poder soberano es siempre absoluto. En su obra De Cive, Hobbes afirma en forma tajante lo siguiente: "De lo dicho se desprende con toda claridad que en todo Estado perfecto (esto es, en el que no les asiste ningún derecho a los ciudadanos para usar su fuerza a su arbitrio en orden a su propia conservación, o sea,

\footnotetext{
${ }^{9}$ Tully, James: Approach to Political Philosophy: Locke in Contexts, 1993, p. 288.

10 Tully, James: Approach to Political Philosophy: Locke in Contexts, 1993, p. 288.

${ }^{11}$ Hobbes, Thomas: Leviatán, edición Fondo de Cultura Económica, 2003, II, Cap. 6,
} 
donde se excluye el derecho de la espada privada) reside en alguno el poder supremo, que es el mayor que pueden conceder con derecho los hombres, y mortal alguno poseer en sí mismo. A este poder, que es el máximo que puede transferirse a un hombre, lo llamamos ABSOLUTO ( $v o$ camus ABSOLVTVM $)^{12}$.

La segunda tendencia, que Tully llama intelectualista, tiene a Tomás de Aquino como su figura fundadora ${ }^{13}$. Para Aquino el hombre es naturalmente libre. Sin embargo, su concepción de la libertad difiere del voluntarismo. La libertad, para Aquino, no es el poder de hacer lo que se quiere, sino la disposición de actuar siguiendo los dictámenes de la ley natural ${ }^{14}$. Y ésta, a su vez, es el conjunto de preceptos morales que el hombre descubre en su propia razón como norma que regula y mide sus actos. Estos preceptos aparecen en la razón como objetivamente obligatorios en la orientación de los actos que conducen al hombre a la realización de su fin natural. Así, esta escuela le confiere a la moral y a la política un fundamento objetivo, pues sus normas mandan la realización de ciertos actos que para el voluntarismo son de libre elección. Desde el punto de vista político, siguiendo esta matriz intelectualista, Francisco Suárez (1548-1617) sostiene que "el hombre es libre por naturaleza y no está sometido a nadie que no sea su Creador"15. De ahí se sigue, que el dominio de un hombre sobre otro "va contra el orden natural e implica una tiranía". Pero, los hombres son naturalmente políticos y necesitan organizarse y ser gobernados, tanto para realizar el bien humano individual como el común. Y para ser gobernados es necesario que exista un gobierno dotado de una forma, o sea, un régimen político. Suárez sostiene que según la ley natural los hombres disponen del poder de darse un régimen político: adoptar concretamente una forma de gobierno "depende de la libre decisión de los hombres" ${ }^{16}$. De este modo, los hombres no están obligados a elegir un determinado régimen, como la monarquía, por ejemplo, aun cuando ésta sea el mejor, según

${ }^{12}$ Hobbes, Thomas: De Cive, en edición C.S.I.C. y Editorial Debate, S.A., 1993, Cap. VI, parágrafo 13, p. 60. Tully, por el contrario, no sitúa a Hobbes en esta posición, pues en su teoría los hombres no disponen libremente de sus vidas y, por consiguiente, no pudiendo alienar lo que tienen, son incapaces de generar un absolutismo radical. O sea, un absolutismo que en forma irrestricta disponga de la vida y la muerte de los sujetos. Para Tully el autor modelo de esta teoría es John Selden (Tully: Approach to Political Philosophy: Locke in Contexts, 1993, p. 289).

${ }^{13}$ Tully, James: Approach to Political Philosophy: Locke in Contexts, 1993, p. 288.

14 Tomás de Aquino: Suma de Teología, Vol. II, Biblioteca de Autores Cristianos, 1993; I, I, cuestiones 90-97, pp.702-759.

${ }^{15}$ Suárez, Francisco: Tractatus de Legubus ac Deo Legislatore, edición Consejo Superior de Investigaciones Científicas, Instituto Francisco de Vitoria, 1977, Libro III, Cap. 1, p. 6.

${ }^{16}$ Suárez, Francisco: Tractatus de Legubus ac Deo Legislatore, III, 4, p. 37. 
Suárez, sino cualquier régimen que realice el bien común. Ahora bien, si la libre decisión de los hombres es la causa de la organización política, quiere decir que los hombres "individualmente considerados, por la naturaleza de las cosas, poseen parcialmente — por así decir— la facultad de constituir o establecer una comunidad perfecta, pero desde el momento mismo que la constituyen, resulta en toda ella este poder (resultat in tota illa haec potestas)"17. Como, según Suárez, la ley natural no obliga a la comunidad a gobernarse directamente, ella puede transferirlo a otro sujeto, un individuo o una asamblea, para investirlo del poder soberano (potestas). La conclusión de Suárez es que siempre que un régimen se constituye legítimamente es porque el pueblo o comunidad, próxima o remotamente, lo ha establecido, "y no puede alcanzarse de otra manera para que sea justo"18. Esta tesis suareciana se inscribe en una concepción sobre el origen divino indirecto o remoto del poder político. Suárez sostiene que el poder político de gobernar, en efecto, procede de Dios, pero su atribución a una persona concreta (un individuo o una asamblea) "resulta de la concesión del pueblo"19. Así, según Suárez, es la comunidad considerada como un todo la que aliena la libertad natural y la transfiere a un soberano ${ }^{20}$. En el caso específico de que el titular del poder soberano sea un individuo, la monarquía resultante es limitada o moderada, porque, aunque el soberano está sobre la ley civil, debe legislar ciñendo su potestad legislativa a la ley natural. Limitaciones que en realidad admiten, en la práctica, un poder monárquico absoluto. Hugo Grocio (1583-1645) y Samuel Pufendorf (1532-1694) difieren con los intelectualistas comunitarios en el sujeto que aliena la libertad natural, pues en ellos no es la comunidad o el pueblo sino los individuos los que hacen la transferencia de potestad política. Éstos transfieren su libertad para ejecutar la ley natural, en vistas a su propia conservación, y crean un soberano que debe conformar su poder a la ley natural. Además, Grocio reduce el ámbito de la ley natural a la preservación de sí mismo y al respeto de los derechos individuales del otro. De este modo, el acto de alienación no puede sino generar un soberano cuyo deber es proteger derechos exclusivos. Tully sostiene que el resultado de la propuesta de Grocio vacía a la ley natural de su función de norma que opera como justicia distributiva ${ }^{21}$. Pues, en efecto, si al soberano grociano solamente le corres-

${ }^{17}$ Suárez, Francisco: Tractatus de Legubus ac Deo Legislatore, III, 4, p. 38.

${ }^{18}$ Suárez, Francisco: Tractatus de Legubus ac Deo Legislatore, p. 59. Suárez, en relación al poder de legislar, dice que éste, "en virtud solamente de la naturaleza de las cosas - ex sola rei natura - no radica en ningún individuo concreto, sino en la colectividad de hombres -in hominum collectione (Tractatus de Legubus ac Deo Legislatore, III, 2, p. 21).

${ }^{19}$ Suárez, Francisco: Tractatus de Legubus ac Deo Legislatore, III, 4, p. 43.

${ }^{20}$ Tully, James: Approach to Political Philosophy: Locke in Contexts, 1993, p. 289.

${ }^{21}$ Tully, James: Approach to Political Philosophy: Locke in Contexts, 1993, p. 289. 
ponde garantizar derechos individuales, no le corresponde, en cambio, aplicar un criterio de distribución de bienes comunes entre los individuos. Este criterio solamente encuentra su legitimidad en la concepción de la comunidad como un todo. Y ello demuestra el individualismo fuerte de sus sostenedores.

Pero Grocio y Pufendorf abren un campo de debate al postular que los individuos pueden alienar su facultad de gobernarse a sí mismos tal como pueden alienar su libertad individual y hacerse esclavos. Grocio, en el libro I, capítulo III de su obra Derecho de la Guerra y la Paz, afirma que es errónea la opinión de los que sostienen que el "poder supremo está en todas partes y sin excepción en el pueblo" 22 . Y el argumento que expone para probar su tesis es el siguiente: "a cualquier hombre le es lícito entregarse privadamente como esclavo a quien quisiere, según se ve, ya por la ley hebrea, ya por la ley romana; ¿por qué, pues, no ha de ser lícito a un pueblo libre entregarse a uno o a muchos, de manera que traspase a él enteramente el derecho de gobernarse, sin quedarse con parte alguna de ese derecho?"23. Pufendorf sigue esta misma línea argumental, pero de un modo más analítico. Según este autor, a medida que la población humana se multiplicó y sus actividades se diversificaron, los mejor dotados y más ricos "arrendaron" el trabajo de los menos dotados y más pobres. A un nivel más avanzado de desarrollo de la sociedad, los contratos de corto plazo de los servidores se fueron transformando en contratos de largo plazo. Esta evolución, estimulada por las necesidades y las desigualdades humanas, culminó con la aparición "natural" de la esclavitud, pues surgió la venta de la libertad individual a terceros. Según Pufendorf, tal como vendemos y compramos bienes usando el contrato, los individuos podemos transferir a otro, y en su beneficio, nuestra propia libertad, y con ella las fuerzas de nuestros cuerpos y energías naturales ${ }^{24}$. Si el ámbito legítimo del contrato admite la servidumbre individual voluntaria, se puede inferir que también permite que un pueblo aliene su libertad natural de hacer lo que estime conveniente para asegurar su propia conservación. Y esto es justamente lo que el pueblo hace a través del pacto de sujeción, por cuyo intermedio se puede transferir total y perpetuamente el gobierno de sí mismo a un individuo o una asamblea. Si esta transferencia constituye como soberano a un individuo, su resultado es la creación de una monar-

\footnotetext{
${ }^{22}$ Grocio, Hugo: El Derecho de la Guerra y la Paz, ed. Reus, 1925, Libro I, Cap. III, 8, p. 155.

${ }^{23}$ Grocio, Hugo: El Derecho de la Guerra y la Paz, pp. 155-156.

${ }^{24}$ Pufendorf, Samuel: Le Droit de Nature et des Gens [1732], Centre de Philosophie Politique et Juridique, Université de Caen, 1987, Libro III, VI, Ch. III, pp. 202-209.
} 
quía absoluta. En la época, se distinguían dos modos de originarse el estado de esclavitud. Por una parte, el derecho de gentes, en aquella parte concerniente al ius belli, consagraba la legitimidad de la captura de los vencidos, a los cuales se les podía conmutar la muerte por la pérdida total de su libertad. Y, por otra, el derecho, emanado del libre consentimiento, de vender la propia libertad, asumiendo así el estado de servidumbre o esclavitud voluntaria. Así, Grocio y otros autores afines hacen la analogía entre estos dos modos de originarse la esclavitud y los modos de constituirse el poder soberano. También, entonces, estos últimos serían dos; la transferencia total del derecho natural de autogobierno, libremente consentida a través de un pacto o contrato, a un individuo o a una asamblea, es análogo a entregarse privadamente un individuo a otro como su esclavo; y, en segundo lugar, la integración de un pueblo libre derrotado al poder soberano del conquistador es análogo al caso de los vencidos, en una guerra justa, que aceptan perder su libertad y ser esclavos para conservar sus vidas. Ambas vías, por institución (alienación voluntaria a través del pacto) o por conquista (alienación forzada), como llama Hobbes a los modos de constituirse el soberano, desembocan en un régimen absolutista.

Esta rápida visión de las principales corrientes de la teoría política y sus representantes, nos revela un masivo consenso en la libertad natural del hombre. De esta premisa capital algunos deducen un sistema político con poderes limitados y otros con poderes absolutos. Todos admiten, además, la legitimidad de los tres regímenes que Aristóteles clasifica conformes al bien común, es decir, la monarquía, la aristocracia, la politeia o democracia recta. Y, por lo mismo, ninguno de ellos supone la sujeción absoluta u originaria de los hombres y la exclusividad de la legitimidad de un solo régimen: la monarquía de derecho divino. Ésta es la razón que me induce a llamar "radical" la teoría de Filmer, que es el epítome del paradigma absolutista. En la próxima sección se hace un recuento de los hitos centrales de la argumentación de este autor.

\section{La teoría radical monárquica de derecho divino}

Filmer no solamente es radical en su tesis, sino también en su fundamentación. Otros autores, como Bossuet, sostienen una sujeción absoluta y la fundamentan en las Sagradas Escrituras ${ }^{25}$, pero no en una doctrina adánica. Y Hobbes llega a la conclusión de la sujeción absoluta sobre argumentos puramente racionales.

25 Bossuet, Jacques-Bénigne: Politique Tiréedes des Paroles de la Ecriture Sainte, Librairie Droz, 1967, Libro IV, pp. 93-113. 
Los argumentos de Filmer que postulan la sujeción absoluta, se abren a tres campos. En primer término, afirma Filmer, Dios les impuso a los hijos de Adán la sujeción absoluta a su padre. En segundo lugar, Adán recibió de Dios la propiedad privada sobre todo lo existente en la tierra. Y, en tercer lugar, Dios le dio a Adán la facultad de trasmitir su poder absoluto a su descendencia por vía de la primogenitura ${ }^{26}$. La tesis fundacional de Filmer está resumida en un texto que no es del Patriarca, sino de la obra titulada Consideraciones sobre Aristóteles, Hobbes...: "Si Dios creó a Adán, y de un pedazo suyo hizo a la mujer, y por generación de ambos, como parte de ambos, se propagó toda la humanidad; si, además, Dios dio a Adán no sólo el dominio sobre la mujer y sobre los hijos que habían de proceder de ellos, sino también sobre toda la tierra para que la dominase y sobre todas las criaturas de ella, de modo que mientras Adán vivió, ningún hombre pudo reclamar ni disfrutar nada a no ser por concesión, asignación o autorización suya"27.

Filmer recurre al Antiguo Testamento para extraer de sus textos su visión del poder de sujeción de los primeros padres y patriarcas, que no solamente es para juzgar crímenes capitales, sino para hacer la guerra y la paz con otros pueblos. La tesis de Filmer es que el poder paternal de Adán es de suyo político, pues contiene todo aquello que caracteriza a la "soberanía que se encuentra en todo monarca" ${ }^{28}$. La conclusión del libro I del Patriarca dice así: "Si comparamos los derechos naturales de un padre con los de un rey, encontramos que son una misma cosa, sin ninguna diferencia entre ellos, más que en su latitud o extensión: como el padre sobre una familia, así el rey extiende su solicitud sobre muchas familias para preservar, alimentar, vestir, instruir y defender a toda la comunidad"29.

En el capítulo II de su tratado, titulado "Es Antinatural que el Pueblo Gobierne o Elija a sus Gobernantes", Filmer desarrolla sus ideas contra la participación de los individuos en el establecimiento del poder político, o, más específicamente, en la instauración de la monarquía, que es el único régimen aceptado por Dios. Entre sus afirmaciones más importantes hay

${ }^{26}$ Filmer, Robert: Patriarca o el Poder Natural de los Reyes, Instituto de Estudios Políticos, 1966, Cap. I, p. 9. En el capítulo II, p. 26 de su libro, Filmer nos da ejemplos de la ley positiva persa y romana que prescribían el derecho del padre a disponer de la vida y la muerte de sus hijos: derecho que, según el autor, fue ampliado, con posterioridad a la Ley de las Doce Tablas, para otorgarle a su titular el poder de "vender a sus hijos hasta dos o tres veces".

${ }^{27}$ Este texto aparece citado por Locke, en su Primer Tratado del Gobierno, Cap. 2, p. 111.

${ }^{28}$ Filmer, Robert: Patriarca o el Poder Natural de los Reyes, Cap. I, p. 9.

${ }^{29}$ Filmer, Robert: Patriarca o el Poder Natural de los Reyes, Cap. I, p. 16. 
que destacar aquella que dirige contra Aristóteles y que reafirma el texto recién citado. Aristóteles afirma, según Filmer, que los primeros reyeshéroes fueron elegidos por el pueblo, motivados por distintas razones, tales como la excelencia de sus virtudes militares en beneficio de la defensa armada de la comunidad, o el mérito de haberles trasmitido un saber o un arte productivo ${ }^{30}$. Son motivaciones que encontramos en muchas opiniones y conjeturas acerca de las primeras monarquías electivas, por ejemplo en autores tan distantes y diferentes como Platón, Polibio, Cicerón, Tomás de Aquino y Maquiavelo. Filmer califica esa hipótesis sobre el origen del poder político como una fantasía y una insensatez. Este argumento nos permite destacar la autoridad que tiene la Sagrada Escritura para el autor, cuyos relatos, según su interpretación, no pueden ser nunca una fantasía, como es para él la conjetura aristotélica sobre la elección de los primitivos reyes-héroes de la tradición griega.

El punto sustantivo que pretende fundamentar Filmer es que Dios nunca trasmitió el poder soberano monárquico por otra vía que por la paternidad y el patriarcado. En este sentido, el autor no puede aceptar la distinción que establece Aristóteles entre poder político y poder doméstico o económico, que hacen suya Suárez, Grocio y Pufendorf. Por esta razón, Filmer focaliza su crítica contra Aristóteles sustentado que si bien se puede aceptar que en la "casa" (oikía) hay dos tipos de sociedades distintas — una configurada por el marido y la esposa y otra por el señor y los siervos y esclavos - no se sigue de ello que la sociedad familiar, doméstica o económica y la política sean diferentes. En consecuencia, al demostrar que la familia está compuesta de dos asociaciones "no" se demuestra que una familia y una nación sean cosas distintas", por lo tanto, ambas son lo mismo $^{31}$.

El autor del poder político, en suma, es Dios, quien lo habría trasmitido directamente a Adán. Ese poder es de la misma naturaleza que el poder del padre sobre su familia; y es, a su vez, el paradigma del poder del patriarca o pater patriae sobre su nación. Este poder es, además, por voluntad divina, un dominio o derecho privado de Adán sobre todos los bienes de la tierra, pues Dios se los habría donado en términos absolutos. A tal punto, que los hijos y descendientes de Adán, mientras estuvo vivo, dispusieron de bienes materiales solamente a título de usufructuarios ${ }^{32}$.

\footnotetext{
${ }^{30}$ Filmer, Robert: Patriarca o el Poder Natural de los Reyes, Cap. II, p. 20.

${ }^{31}$ Filmer, Robert: Patriarca o el Poder Natural de los Reyes, Cap. II, p. 24. En p. 16 leemos: "Si comparamos los derechos naturales de un padre con los de un rey, encontraremos que son una misma cosa, sin ninguna diferencia entre ellos más que en su latitud y extensión".

${ }^{32}$ Filmer, Robert: Patriarca o el Poder Natural de los Reyes, Cap. II, p. 27.
} 
Así, Dios habría instituido a la monarquía como el único régimen legítimo y bueno. Y la habría dotado de poderes absolutos sobre la vida y los bienes de sus súbditos. El último capítulo de la doctrina político-teológica de Filmer es su teoría sobre la transmisión de este poder político a las generaciones humanas sucesivas. Según Filmer, después del diluvio universal, Noé repartió el "mundo entre sus tres hijos para que lo poblasen. La descendencia de los hijos de Noé se dispersó, después de la confusión de lenguas, y la consiguiente diferenciación de la humanidad en naciones o pueblos distintos (Babel)"33. A partir de allí, se difundió el modelo adánico del gobierno monárquico del patriarca sobre sus naciones. Así se reinició para siempre entre todos los pueblos el gobierno natural de los reyes y la sujeción absoluta de sus gobernados. Filmer sostiene que en ningún momento interviene la voluntad humana en la transmisión de este poder monárquico, pues éste se autogenera hereditariamente por vía de la primogenitura. De este modo, en toda la humanidad, dividida según las "familias" descendientes de Noé y sus hijos, "en las cuales los 'padres' eran cabezas y príncipes" 34 , se impone el designio divino de la gobernación monárquica absoluta y la sucesión del poder político a través de los primogénitos.

Filmer considera que es absurdo sostener que actualmente los reyes son los padres de su pueblo. Pero afirma que si bien los reyes no son los "padres naturales" de su pueblo, sí son, o así se les debe considerar, "los más próximos sucesores de aquellos primeros primogénitos que fueron en un principio los padres naturales de su pueblo, y los herederos de sus derechos al ejercicio de la suprema jurisdicción"35.

En el capítulo III del Patriarca, su autor sistematiza y discute la anterioridad natural del poder soberano del rey. A partir de la premisa de que ese poder es recibido directamente de Dios, sin que esté mediatizado por la participación del pueblo ${ }^{36}$, su carácter solutus, separado y libre de cualquier sujeción, lo sitúa sobre la ley positiva. La analogía recurrente con el poder paternal reaparece nuevamente en la argumentación: "el padre de familia gobierna por la única ley de su voluntad y no por las leyes y voluntades de sus hijos y servidores"37. El padre vela por la preservación y bienestar de la familia. Esta ley es también la primera ley del gobierno monárquico: "el rey por la misma ley de la naturaleza está obligado a mantener este principio fundamental: que la salud del pueblo es su primera

\footnotetext{
${ }^{33}$ Filmer, Robert: Patriarca o el Poder Natural de los Reyes, Cap. I, p. 9.

${ }^{34}$ Filmer, Robert: Patriarca o el Poder Natural de los Reyes, Cap. I, p. 10.

${ }^{35}$ Filmer, Robert: Patriarca o el Poder Natural de los Reyes, Cap. I, p. 13.

${ }^{35}$ Filmer, Robert: Patriarca o el Poder Natural de los Reyes, Cap. III, p. 52.

${ }^{37}$ Filmer, Robert: Patriarca o el Poder Natural de los Reyes, Cap. III, p. 53.
} 
ley”. Esta ley impone al rey la supremacía del bien común y el autocontrol de su propio poder, pero no su sometimiento a la ley positiva, de la cual él es la fuente, como supremo legislador y juez. De esta libertad del príncipe, por delegación, reciben poderes limitados y subordinados las personas e instituciones del reino. Filmer analiza la historia del parlamento inglés, poniendo énfasis en que esta institución es "del" rey, es siempre "su" parlamento. Ello se expresa en forma meridiana, según nuestro autor, en distintos estatutos del reino, entre los cuales cita el Estatuto de Westminster que comienzan así: "Éstas son las actas del Rey Eduardo I, hechas en $s u$ primer Parlamento General, por su Consejo General, y el asenso de obispos, abades, priores, condes, barones y toda la comunidad del reino, etc." ${ }^{38}$. Otros ejemplos similares ayudan a Filmer a sostener que el Parlamento, manejado por el Consejo real, es un órgano político del rey. Podemos imaginar el impacto de la publicación del Patriarca, en 1679, cuando la querella entre el Parlamento y las prerrogativas reales prefiguraban el desenlace revolucionario de 1689.

En el primer capítulo de su Primer Tratado del Gobierno, Locke sintetiza la doctrina de Filmer en dos proposiciones. Nos dice, "su doctrina se encierra en un pequeño círculo que no es ni más ni menos que éste: (1) Todo gobierno es monarquía absoluta y (2) Ningún hombre nace libre ${ }^{39}$. La doctrina de Filmer, reducida a lo esencial, establece que dado que ningún hombre nace libre, "nunca pueden tener libertad para elegir ni sus gobernantes ni las formas de gobierno" 40 . De estas premisas Locke deduce que según Filmer "el poder de los príncipes es absoluto y de derecho divino, ya que los esclavos no tienen jamás derecho a pactar ni a consentir" ${ }^{\prime 1}$. Negada la libertad natural, automáticamente se niega también el ejercicio de las facultades humanas a través de las cuales ella se expresa. Así, queda establecido el principal desafío que Locke debe encarar en el Segundo Tratado sobre el Gobierno, fundar el poder político en la libertad y el consentimiento.

La postura de Filmer es realmente radical, pues rompe con todas las tradiciones teóricas existentes. No solamente con los autores contractualistas modernos (sus antagonistas naturales), sino con sus contemporáneos "papistas" o "reformados", que de algún modo prosiguen la tradición de la soberanía popular que se origina en la Edad Media.

\footnotetext{
${ }^{38}$ Filmer, Robert: Patriarca o el Poder Natural de los Reyes, Cap. III, p. 80.

${ }^{39}$ Locke, John: Primer Tratado sobre el Gobierno, I, 1, p. 101.

${ }^{40}$ Locke, John: Primer Tratado sobre el Gobierno, I, 1, p. 103.

${ }^{41}$ Locke, John: Primer Tratado sobre el Gobierno, I, 1, p. 103.
} 


\section{La refutación de Locke a la monarquía absoluta de derecho divino, la libertad natural y el derecho a la resistencia civil}

Filmer propone la más radical de las doctrinas de la monarquía absoluta de derecho divino. La respuesta de Locke está desplegada en dos grandes capítulos. El primero está contenido en su Primer Tratado sobre el Gobierno, y su propósito es desmontar los argumentos de Filmer desde un punto de vista bíblico y teológico. El segundo capítulo está principalmente concentrado en el Segundo Tratado de Gobierno y las premisas del veto absoluto al absolutismo provienen principalmente de su teoría sobre el origen de la sociedad política o civil, que emerge de la libertad natural y el consentimiento de los hombres (capítulo VII, secciones 90 a 95). La estructura esencial de esos argumentos sostiene y orienta una concepción más general acerca de la tiranía, que se desarrolla más adelante en el mismo texto (capítulo XVIII), y que, a su vez, enmarca el discurso del autor acerca de la resistencia civil. En consecuencia, en esta segunda parte, seguiremos el hilo conductor recién expuesto.

\section{Locke contra Filmer}

Locke, al iniciar su refutación de Filmer, inscribe a este último entre aquellos autores que sostienen que todos los hombres, por la voluntad divina, salvo uno, han nacido esclavos ${ }^{42}$. Y que, por lo tanto, todos ellos estarían predestinados a la sujeción absoluta bajo una monarquía de derecho divino. Monarquía instituida por Dios y atribuida a Adán y su descendencia por la vía de la primogenitura. Locke anuncia su refutación diciendo que "ni las Sagradas Escrituras ni la razón dicen tal cosa en parte alguna"43.

La primera cuestión que enfrenta nuestro autor es el argumento de Filmer que homologa el poder paternal de Adán al poder político. Su objeción inicial apunta al hecho de que Filmer nunca entrega una noción definitoria de ese poder paternal, que es a la vez político y monárquico. Lo que hace Filmer, en el Patriarca, es describir un presunto poder paternalreal de Adán, según su interpretación del Antiguo Testamento. Filmer, nos dice Locke, hace un recuento de cómo la "paternidad" comienza con Adán y se desplaza, ordenando el mundo y estableciendo jueces, patriarcas y reyes a través de la historia de Israel. Filmer elude dar una definición

\footnotetext{
${ }^{42}$ Locke, John: Primer Tratado sobre el Gobierno, I, Cap. 1, p. 102.

${ }^{43}$ Locke, John: Primer Tratado sobre el Gobierno, I, Cap. 1, p. 102.
} 
esencial del poder paternal como poder político, en abierta contradicción con el método deductivo, que él mismo sustenta en otros escritos ${ }^{44}$. Locke reprocha también a Filmer la mutilación de sus citas bíblicas para dar coherencia a su doctrina: así acontece cuando el mandamiento divino Honra a tu padre y a tu madre, se transforma convenientemente en Honra a tu padre $^{45}$. Obviamente la elisión indebida de la madre potencia, pero a la vez falsifica, la doctrina del carácter absoluto del poder paternal. Más adelante voy a volver sobre este punto.

La descripción del poder paternal de Adán y de los sucesivos patriarcas, como ya vimos, es un poder real sobre sus hijos, dominio sobre todo el mundo, derecho de vida y muerte y derecho de hacer la guerra y la paz. Estos extensísimos poderes han sido otorgados por la ley de Dios a Adán, quien de este modo es "señor de todo". Una vez instituido el poder paternal-real de Adán, éste y su sucesión gobiernan en conformidad a su voluntad, sin sometimiento a ninguna ley humana. Las leyes, nos dice Locke, para Filmer solamente tienen un valor particular, y no universal, restringido a la duración del gobierno de cada rey. Sus sucesores deben convalidarlas, por un acto de su propia voluntad, para que sigan vigentes ${ }^{46}$. $\mathrm{Y}$, por último, si ellas existen es por la simple contingencia de que las guerras u otras obligaciones alejaban al rey de sus súbditos y en su ausencia ellos no podían conocer cuál era su voluntad. Las leyes vinieron a suplir ese vacío ${ }^{47}$. Así, el monarca absoluto está por encima de la ley, de la cual él es autor, y, a la vez, su autoría se ejerce a partir de un voluntarismo subjetivo también absoluto y sin límites. Esta teoría, por ejemplo, echaría por tierra el Tratado sobre la Ley de Tomás de Aquino.

Locke recurre a otros textos del mismo Filmer para exponer el carácter "terrible" del poder absoluto que el monarca adánico puede ejercer sobre sus sujetos. A Adán se le entrega poder de vida y muerte, venta, donación y castración sobre sus hijos. La ley no es otra cosa que "la voluntad de aquel que tiene el poder supremo del padre" 48 . Se trata, en suma, de un poder "absoluto, arbitrario, ilimitado e ilimitable sobre la vida y libertad de sus hijos y súbditos", que hace de éstos esclavos de quién lo detenta como soberano. La mera descripción de este poder suscita la duda de que Filmer pretenda convencer a sus lectores de las bondades de un gobierno que lo ejerza. Más bien, levanta la sospecha de que busca halagar

\footnotetext{
${ }^{44}$ Locke, John: Primer Tratado sobre el Gobierno, I, Cap. 2, p. 106.

${ }^{45}$ Locke, John: Primer Tratado sobre el Gobierno, I, Cap. 2, p. 106.

${ }^{46}$ Locke, John: Primer Tratado sobre el Gobierno, I, Cap. 2, p. 108.

${ }^{47}$ Locke, John: Primer Tratado sobre el Gobierno, I, Cap. 2, p. 108-109.

${ }^{48}$ Locke, John: Primer Tratado sobre el Gobierno, I, Cap. 2, p. 109.
} 
a los reyes y poderosos ${ }^{49}$, que al leerlo pueden encontrar motivos y legitimidad para ejercer un poder sin límites.

Si solamente hay una descripción de un poder paternal que es puramente conjetural, no hay pruebas teológicas ni racionales que afirmen su verdad (teológica y filosófica). Este punto capital de su doctrina - que carga con el mayor peso de toda la argumentación del Patriarca- se da por supuesto sin prueba $^{50}$. La sola expresión que tiene una apariencia de prueba es la siguiente: "Para confirmar este derecho natural del poder real, encontramos que en el decálogo la ley que ordena obediencia a los reyes está expresada en los términos: Honra a tu padre, como si todo el poder estuviera originariamente en el padre"51. La mutilación del mandamiento, que ya mencionamos, plantea inmediatamente la pregunta que provoca la segunda parte del mandamiento que exige honrar a tu madre. En efecto, ¿por qué no la obediencia a las reinas, como si todo el poder estuviera originariamente en las madres ${ }^{52} \mathrm{Si}$ un argumento fuese válido, también lo sería el otro.

Como afirma Locke, esa fundamentación no es una prueba que demuestre el poder real de Adán y menos el contenido de ese poder. La mera agregación, a la "fundamentación" recién expuesta, de una proposición que sostiene que "la creación hizo al hombre príncipe de su posteridad", no parece válida para concluir que el poder real de Adán queda suficientemente asentado. La estructura del discurso de Filmer, dice Locke, se construye con un "nuevo" sistema de inferencia ${ }^{53}$ obviamente falso. Este falso argumento es adoptado por los militantes del absolutismo como verdadero, no por su estructura lógica y su valor de prueba, sino por la frecuencia con que su autor lo repite ${ }^{54}$.

Una vez tratado el tema del poder paternal de Adán, Locke focaliza su atención en el segundo argumento central de Filmer, a saber: no se puede suponer la libertad de los hombres sin negar la creación. Locke expresa su sorpresa por esta supuesta contradicción entre el acto de creación del hombre por Dios y la libertad natural de éste. Y, por consiguiente, por la validez de la proposición que afirma que si Dios ha creado al hombre, éste es necesariamente sujeto, o sea no libre, en suma, esclavo. Locke sostiene que el acto omnímodo de Dios, a través del cual crea al hombre, consistió en darle existencia desde la nada. Y que la nuda existencia confe-

\footnotetext{
${ }^{49}$ Locke, John: Primer Tratado sobre el Gobierno, I, Cap. 2, p. 110.

${ }^{50}$ Locke, John: Primer Tratado sobre el Gobierno, I, Cap. 2, p. 111.

${ }^{51}$ Locke, John: Primer Tratado sobre el Gobierno, I, Cap. 2, p. 112.

${ }^{52}$ Locke, John: Primer Tratado sobre el Gobierno, I, Cap. 2, p. 112.

${ }^{53}$ Locke, John: Primer Tratado sobre el Gobierno, I, Cap. 2, p. 113.

${ }^{54}$ Locke, John: Primer Tratado sobre el Gobierno, I, Cap. 2, p. 111.
} 
rida por Dios no es incompatible con la libertad del género humano, derivado de Adán y Eva. El argumento separa y distingue entre la acción divina por la que Dios crea a Adán y la acción divina por la cual Dios podría haberle conferido el poder de dominio que supone Filmer. La confusión que hace Filmer de esos dos actos lo induce a sostener que aunque no había súbditos sobre los cuales ejercer un poder político, Dios le concedió a Adán la potestad absoluta sobre su progenie, o sea, sobre toda la humanidad. "Adán fue rey desde su creación", tal es la tesis de Filmer. Pero, Locke pregunta dónde está la demostración de que Dios hizo un acto de institución de ese poder político en la persona de Adán. Y ni la Sagrada Escritura ni la razón dan base para ello.

Para Locke todo "lo que la providencia ordena o la ley de la naturaleza manda, o la revelación positiva declara, puede decirse de institución divina”, pero Filmer no aporta demostración alguna de que Dios haya instituido un poder político adánico con sujeción absoluta sobre su descendencia y dominio sobre todos los bienes de la tierra ${ }^{55}$. Locke demuestra que Filmer construye su argumento sobre premisas falsas. Filmer dice que "Adán tan pronto fue creado por Dios fue monarca del mundo". Esta proposición puede perfectamente tener un significado distinto al que Filmer pretende darle. Podemos reconstruirla sobre la base de que la razón divina, en tanto regula a la creación, es ley de la naturaleza. Sobre este supuesto tendríamos que decir: una vez que Adán fue creado, por ley de la naturaleza, fue monarca de su posteridad. Y obviamente, es un contrasentido para la razón humana, que es la facultad que nos da acceso a la ley natural, que Adán haya sido rey antes de que hubiese existido población, o sea, súbditos ${ }^{56}$. O, bien, desde la perspectiva de la secuencia temporal de los hechos del relato bíblico: es falso que Adán hubiese sido monarca desde el instante mismo de su creación, y según un derecho de paternidad, siendo así que en esa instancia aún no existía ni Eva, ni los hijos de ambos, y no había acontecido el pecado original ${ }^{57}$. Un contra-argumento similar aplica Locke al dominio de Adán sobre el mundo, inmediatamente anexo a su creación, pues las palabras de Dios en el Génesis 3,16, a las que Filmer atribuye el primitivo título de gobierno adánico, no son pronunciadas sino después de la caída original, y, en consecuencia, con posterioridad al acto de creación de su supuesto titular. Además, es una falsa inferencia que Dios, por donación positiva, nombró a Adán monarca del mundo porque por la ley de la naturaleza le correspondía gobernar a su posteridad, pues si

\footnotetext{
55 Locke, John: Primer Tratado sobre el Gobierno, I, Cap. 3, p. 116.

${ }^{56}$ Locke, John: Primer Tratado sobre el Gobierno, I, Cap. 3, p. 117.

${ }^{57}$ Locke, John: Primer Tratado sobre el Gobierno, I, Cap. 3, p. 117.
} 
esa ley natural establece tal gobierno no es necesario tal donación positiva $^{58}$.

Además de que el argumento no prueba donación alguna, su estructura es circular. En efecto, si Adán, por ley de la naturaleza, es gobernante de su posteridad, también por ley de la naturaleza es monarca del mundo. De donde se sigue la proposición tautológica que "Adán es gobernante por ley de la naturaleza porque es gobernante por ley de la naturaleza"59 (todo monarca es gobernante).

Refutada la naturaleza absoluta y monárquica del poder paternal de Adán, Locke establece que los hombres fueron creados por Dios libres e iguales, dotados de las mismas facultades y el mismo poder para desprender la ley de la naturaleza de su propia razón y servirse de ella para decidir acerca del desarrollo de sus vidas.

Una tercera cuestión que Locke confronta es el argumento sobre la sucesión de la monarquía de derecho divino instituida junto con la creación de Adán. Según Filmer, el derecho de Adán a gobernar a su sucesión se trasmitiría a la humanidad por la vía de la primogenitura. Locke observa que si fuese así, siempre habría habido un único monarca del mundo, lo cual es contra-factual, porque nunca ha acontecido en la realidad. Pero, suponiendo válida la interpretación de Filmer de que después de Noé, y en conformidad a la aparición de la diversidad de lenguas y pueblos, los patriarcas y reyes de los nuevos pueblos pertenecieron a la línea primogénita de Adán, la cuestión merece una segunda consideración. Y obviamente, es razonable preguntarse si acaso los reyes actuales — es decir, aquellos del siglo XVII d.C.- son descendientes primogénitos de Adán. Filmer sale al paso de esta pregunta y responde que si bien no hay certeza es probable que sea así. Y que, por lo mismo, de algún modo los padres de los pueblos, sus patriarcas, sus primeros reyes, o eran sucesores directos o indirectos o cercanos a la línea de sucesión legítima. Se puede especular que Filmer pensaba que los poderosos de la historia, ancestralmente estuvieron cerca del poder o fueron los titulares del mismo. Pero el asunto de fondo para Filmer es que los reyes actuales detentan sus títulos en virtud de algún tipo de transferencia regular del poder de Adán. De ahí el carácter sagrado de la transmisión del poder real. Pero todo esta teorización carece de sujetos concretos a los cuales se les pueda aplicar, porque Filmer es incapaz de establecer quién es el heredero de Adán. Dios le dice a Caín que el deseo de Abel "le será sometido y le obedecerá", pero a condición que sea un buen hombre. Además, según el relato bíblico, ambos tienen bienes

${ }^{58}$ Locke, John: Primer Tratado sobre el Gobierno, I, Cap. 3, p. 119.
${ }^{59}$ Locke, John: Primer Tratado sobre el Gobierno, I, Cap. 3, p. 118. 
y familias separadas que parecen regirse por la autoridad de cada cual. Y no hay pruebas contundentes de que esa independencia fuese compatible con una autoridad absoluta de Caín sobre sus hermanos. Locke agrega información sobre los derechos transmitidos a los primogénitos en el Antiguo Testamento, que prueban que nunca fueron absolutos y que la historia bíblica relata múltiples excepciones a los derechos de primogenitura, como es el caso emblemático de Jacob. De este modo, Locke, al menos, deja claro que Filmer no prueba la transmisión del poder absoluto del cual sería titular, ni de él a los patriarcas, ni de los patriarcas a los jueces, ni de los jueces a los reyes, ni de los reyes primitivos a los reyes antiguos, y así sucesivamente. El sistema hereditario se desploma por su base.

Locke cuestiona a Filmer por su interpretación bíblica y alega que carece de un método que incluya el análisis sobre la diversidad de sentidos que tienen las palabras y las proposiciones del Antiguo Testamento. Este grave déficit hermenéutico inhabilita a Filmer para descubrir la conexión de las partes del relato bíblico, y su coherencia y unidad interna, y hacer comparecer la verdad de la revelación. Locke, aplicando su método interpretativo, llega a conclusiones completamente distintas sobre la sujeción natural de la mujer y los hijos de Adán y sobre el dominio privado de éste sobre la tierra. Establece que Dios no le dio a Adán, o al padre y esposo originario, los poderes criminales que le atribuye Filmer (muerte, venta, castración, etc.). Y que Dios puso a disposición del género humano, en propiedad común, los bienes de la tierra. No entro en la trama argumental de las refutaciones de Locke, por su extensión y porque creo que son suficientes aquellas que he expuesto sobre las premisas capitales del sistema absolutista de Filmer: la sujeción natural de los hombres; la monarquía de derecho divino como único régimen legítimo instituido por Dios, y la sucesión del poder monárquico por la vía de la primogenitura.

\section{Absolutismo y tiranía}

En el Segundo Tratado sobre el Gobierno, Locke expone sus objeciones fundamentales a la monarquía absoluta, desde el punto de vista de la libertad natural de los individuos. Hay que destacar que los autores principales y más influyentes de los siglos XVI y XVII fundan sus concepciones sobre el Estado y el gobierno en la libertad natural. En el primer capítulo, sección 1, de este ensayo se hace un bosquejo de la amplia variedad de tendencias y autores que suscriben esa concepción. En línea con los autores contractualistas de su época, Locke sostiene que los hombres son naturalmente libres, iguales e independientes. En estado de naturaleza, el ser 
humano es completamente libre para ordenar sus actos y disponer de sí mismo y sus bienes como mejor le parezca. Esta libertad se enmarca dentro de los límites de la ley natural y entraña una absoluta independencia de la voluntad de los otros ${ }^{60}$. No hay, en consecuencia, sujeción alguna, pues cada cual se gobierna a sí mismo. Además, todos los hombres son iguales, en el sentido que son miembros de una misma especie, están dotados de las mismas facultades y despliegan sus vidas en un espacio de reciprocidad, en el cual nadie tiene más poder, autoridad o jurisdicción que el otro.

La ley de la naturaleza es la ley de la razón, porque el hombre ha sido dotado por Dios de la facultad de extraer de su propia razón la regulación o medida de sus actos, tanto de aquellos relacionados consigo mismo como los relacionados con el otro. La ley primaria de la naturaleza o de la razón le ordena al hombre preservar su vida, su libertad y sus bienes. Y, enseguida, cuidar al otro, porque cada cual está a cargo de la preservación de la humanidad.

Aunque Locke no usa el término "autonomía", es claro que su concepción de la libertad y la independencia de cada cual se puede interpretar como gobierno autónomo de sí mismo. Sin embargo, el estado de naturaleza es una esfera de vida insegura e incierta. Aunque la ley de la razón provee la guía normativa para que cada cual pacíficamente se preserve a sí mismo y al otro, se carece de las garantías, ciertas y seguras, que la sociedad políticamente organizada les procura a los individuos. En estado de naturaleza, los individuos carecen de las ventajas de un legislador común, de un juez tercero e imparcial y de la fuerza pública, habilitada para asegurar la aplicación de la ley y la sentencia judicial. Por esta razón, sostiene Locke, los hombres abandonan el estado de naturaleza. Cada vez que un número equis de individuos se separan del estado de naturaleza, lo hacen para, a través de un contrato, o sea por consentimiento expreso y formal, dar forma o incorporarse a una sociedad civil o política. En este acto, a la vez, crean por consentimiento mayoritario un régimen político, al cual invisten del poder fiduciario para que los gobierne en su nombre y con miras a su bien común.

En consecuencia, Locke no solamente postula la libertad natural del hombre, sino que proyecta esa libertad en la formación del Estado y del gobierno $^{61}$. La libertad sigue siendo, en el seno de la sociedad o cuerpo

\footnotetext{
${ }^{60}$ Locke, John: Second Treatise of Government, Blackwell and Basil, 1976, Cap. II, p. 4-10.

${ }^{61}$ Hay que tener en cuenta que Locke no usa el término Estado (state) sino sus equivalentes ingleses de la época, o sea, sociedad civil (civil society), sociedad política (political society), cuerpo político (body politic or political body), comunidad política (commonwealth). Además, incidentalmente usa el término acuñado por Hobbes, Leviatán, y también comunidad (community).
} 
político, el fundamento de la vida política, porque siendo el poder del régimen político o gobierno un poder fiduciario, esencialmente revocable, siempre la sociedad civil conservará la última decisión o poder soberano. Ésta es la razón por la cual aquello que determina la constitución del régimen político es la delegación, por la sociedad civil a través del consentimiento mayoritario, del poder legislativo. La creación de la sociedad política y el gobierno, por medio del contrato y la decisión mayoritaria, siempre resulta en la constitución de un poder político limitado o moderado. En primer término, por la supremacía del poder legislativo y el imperio de la ley; enseguida, por la división del poder; y, en tercer lugar, por el fin mismo del contrato: asegurar a los miembros de la sociedad política el disfrute pacífico y tranquilo de sus vidas, libertades y bienes.

El dispositivo conceptual recién expuesto —que el lector puede encontrar desarrollado en los capítulos VII y VIII del Segundo Tratado del Gobierno $^{62}$ - sirve de plataforma para la crítica y el veto que Locke pone a la monarquía absoluta. La primera y principal tesis de Locke es que la monarquía absoluta es incompatible con la sociedad civil o política como tal. En consecuencia, el mero hecho de constituirse, por contrato, una sociedad civil, queda rechazada la posibilidad de una monarquía absoluta. Ésta, dice Locke, ni siquiera puede considerarse una forma política ${ }^{63}$. El fundamento es claro: si los individuos crean la asociación política para disponer de la protección cierta y segura de sus vidas, libertades y bienes, es absurdo pensar que van a crear, para la consecución de ese fin, un poder absoluto que ex definitione dispone discrecional y totalmente de la vida, la libertad y los bienes de sus súbditos.

El príncipe absoluto reúne en su persona todos los poderes del Estado (legislativo, judicial y ejecutivo). Dado que este príncipe detenta la ley, la judicatura y la fuerza pública en sus manos, sus súbditos no tienen garantías de justicia e imparcialidad, y, por lo mismo, seguridad y certeza de que el daño que el soberano o sus delegados puedan causarle sea reparado o castigado ${ }^{64}$. Puesto que el príncipe absoluto está más allá y por encima de la ley, y no existe una potencia legislativa que limite su poder, en realidad no forma parte del cuerpo político o sociedad civil, y, en virtud de su peligrosidad, está en estado de guerra con ella.

Otros argumentos de Locke, contra la monarquía absoluta, establecen que a nadie debe sorprender que en tal sistema haya jueces y funcionen tribunales. Pero, sostiene Locke, detrás de esa justicia no hay amor a la

${ }^{62}$ Locke, John: Second Treatise of Government, Cap. VII y VIII, 77-122, pp. 39-63.

${ }^{63}$ Locke, John: Second Treatise of Government, Cap. VII, 90, p. 44.

${ }^{64}$ Locke, John: Second Treatise of Government, Cap. VII, 90 y 91, pp. 44-45. 
humanidad, sino el interés egoísta del dueño del rebaño que procura que sus animales no se maten entre sí y con ello se menoscabe su patrimonio ${ }^{65}$. El caso de la monarquía de iure divino, interpretada a la luz del contrato, es como si los hombres, "al abandonar el estado de naturaleza y al entrar en sociedad, se hubieran puesto de acuerdo en que todos ellos, menos uno, habían de estar sometidos a la fuerza de las leyes". Y que, por lo tanto, ese uno conservase "toda la libertad propia del estado de naturaleza, aumentada por el poder y desenfrenada por la impunidad"66. Nadie querría salir del estado de naturaleza, confiriéndole tal excepción a ese "uno", pues ello sería tan insensato como para querer conservar la vida, y, a la vez, adoptar como protección ser devorados por leones ${ }^{67}$.

En el origen de las monarquías es posible que se le entregase por consentimiento tácito un poder de gobierno a hombre sabio y justo, un verdadero juez capaz de dirimir los conflictos de las personas ${ }^{68}$. Y que el carácter sagrado atribuido a esa costumbre, que fluye de la "simplicidad negligente e imprevisora de las primeras edades" 69 , hubiese consolidado esos regímenes. Pero, después de los sabios, surgieron los tiranos y el pueblo experimentó la inseguridad y la incertidumbre de sus vidas, libertades y posesiones. Solamente en ese momento, los hombres descubrieron que ese régimen político era incompatible con los fines de la sociedad civil $^{70}$. Y que, por lo mismo, había que crear, por consentimiento mayoritario, un poder legislativo soberano, un poder colectivo llamado parlamento $^{71}$. De este modo, toda la sociedad civil quedaría colocada bajo la ley, sin que nadie ni ninguno pudiera substraerse de su imperio y su fuerza.

Locke, en la parte final de su Segundo Tratado sobre el Gobierno desarrolla su teoría sobre la tiranía. Se trata de un tema que tiene resonancias históricas, pues su tratamiento pertenece al canon del pensamiento político antiguo y medieval. Nuestro autor analiza la tiranía desde la perspectiva de su concepción de la libertad, el consentimiento, la constitución de la sociedad civil y el gobierno moderado. Toma como punto de partida de su análisis el concepto de usurpación ${ }^{72}$. Nos dice, en efecto, que la usurpación es el ejercicio del poder al cual otro tiene derecho. El usurpador se apodera del poder de otro y lo ejerce sin derecho a él, puesto que no le

\footnotetext{
${ }^{65}$ Locke, John: Second Treatise of Government, Cap. VII, 93, p. 47.

${ }^{66}$ Locke, John: Second Treatise of Government, Cap. VII, 93, p. 47.

${ }^{67}$ Locke, John: Second Treatise of Government, Cap. VII, 93, p. 47.

${ }^{68}$ Locke, John: Second Treatise of Government, Cap. VII, 94. p. 48.

${ }^{69}$ Locke, John: Second Treatise of Government, Cap. VII, 94, p. 48.

${ }^{70}$ Locke, John: Second Treatise of Government, Cap. VII, 94, p. 48.

${ }^{71}$ Locke, John: Second Treatise of Government, Cap. VII, 94, p. 48.

${ }^{72}$ Locke, John: Second Treatise of Government, Cap. XVII, 197 y 198, pp. 99 y 100;
} Cap. XVIII, 199, p. 100 
pertenece $^{73}$, pero lo hace en conformidad a la estructura formal y al fin del poder usurpado. Así, por ejemplo, el usurpador se hace del poder monárquico que le pertenece a su padre, pero lo ejerce adecuándose a la constitución de ese poder. El usurpador, en tanto solamente es un usurpador y no comete otros crímenes, no altera la naturaleza del poder que hace indebidamente suyo, y, por lo mismo lo ejerce sometido al derecho. Locke se refiere, al hablar de este tema, de regímenes políticos constituidos legítimamente.

El tirano, en cambio, ejerce el poder fuera de los límites del derecho $^{74}$. Locke sigue la concepción tradicional de la tiranía, que define al tirano como un gobernante que no procura el bien de la comunidad, sino el suyo propio, violando el bien común ${ }^{75}$. Pero, en términos lockeanos, eso significa que no gobierna en conformidad a la ley que se origina en el poder legislativo, y que, por lo mismo, no reconoce ni la supremacía de ese poder ni el imperio del derecho. Así, la acción del tirano no se ordena a la finalidad de asegurar el disfrute de la vida, la libertad y los bienes de cada miembro de la sociedad civil, sino a satisfacer su propia voluntad desordenada por las pasiones, ambiciones, venganzas, etc. ${ }^{76}$.

Pero, además, Locke se aleja de la concepción tradicional de la tiranía, porque sostiene que ella no se reduce a ser un vicio o corrupción de la monarquía ${ }^{77}$. Todos los demás regímenes legítimos pueden degenerar en la tiranía. El principio general que enuncia es el siguiente: "siempre que el poder que se ha puesto en manos de 'una o varias' personas, para el gobierno del pueblo y la salvaguardia de sus propiedades, se aplica a otros fines o se usa para empobrecer, acosar o someter a las gentes a los mandatos arbitrarios e irregulares de quienes lo detentan, se convierte inmediatamente en tirano" 78 , sin importar que ese poder esté radicado en "uno o muchos".

Ahora bien, según Locke, quien ejerce el poder fuera de los límites de la ley y se sirve de la fuerza pública para cargar a los súbditos con

\footnotetext{
${ }^{73}$ Locke, John: Second Treatise of Government, Cap. XVII, 197, p. 99.

${ }^{74}$ Locke, John: Second Treatise of Government, Cap. XVIII, 199, p. 100.

75 Locke, John: Second Treatise of Government, Cap. VIII, 200, p. 100. En esta
} sección Locke cita a Jacobo I Estuardo (1566-1625). Se trata de un discurso del rey ante el parlamento, donde el soberano expone la doctrina clásica del poder monárquico moderado o limitado por la ley divina, la ley natural y las leyes positivas fundamentales del reino. Jacobo I de Inglaterra y VI de Escocia (James VI y I), escribió dos libros de teoría política, Basilikon Doron (1599) y The Trew Law of Free Monarchies (1598), que junto con otros escritos y una parte de sus discursos al parlamento inglés están publicados con el título de Political Writings, Cambridge University Press, 1994).

${ }^{76}$ Locke, John: Second Treatise of Government, Cap. XVIII, 201, p. 101.

${ }^{77}$ Locke, John: Second Treatise of Government, Cap. XVIII, 201, p. 101.

${ }^{78}$ Locke, John: Second Treatise of Government, Cap. XVIII, 201, p. 101. 
obligaciones no contempladas por la ley, deja de ser magistrado y pierde la autoridad por la cual era obedecido ${ }^{79}$.

\section{El derecho a la resistencia contra la tiranía}

Locke piensa que los hombres sometidos a un régimen cuyas leyes no son fijas, y donde no hay jueces imparciales, viven en una situación peor que el estado de naturaleza. Como sabemos, el estado de naturaleza tiene grandes desventajas (incertidumbre e inseguridad). Pero estar bajo un gobierno sin leyes ni jueces es mucho peor, pues, la libertad de juzgar cada cual su derecho y el modo de defenderlo, propio del estado de naturaleza, queda totalmente anulada por el soberano absoluto. Y, en consecuencia, lo que ocurre es que los gobernados por ese régimen están reducidos a la esclavitud $^{80}$, rebajados de su condición de criaturas racionales, por denegación de su libertad de juzgar sobre sí mismos o defender su derecho.

El soberano absoluto hace una duplica o sucedáneo del estado de naturaleza, al sumir a sus sujetos en un estado de inseguridad e incertidumbre, provocadas por la ausencia de la ley y el juez común. En esta circunstancia, los individuos tendrán que considerarse a sí mismos en estado de naturaleza frente al soberano absoluto ${ }^{81}$. Y, por lo tanto, asumir la tarea de darse a sí mismos, "lo antes que puedan", la seguridad y salvaguardia para la cual ellos mimos instituyeron la sociedad civil ${ }^{82}$. Esto significa que la sociedad civil o comunidad política, por consentimiento mayoritario, debe instituir un poder legislativo y, por lo mismo, un régimen político nuevo.

La formulación de Locke, referente al sucedáneo del estado de naturaleza, no pretende significar que los individuos retornan a esa situación originaria. No es que se reinserten en la multitudo disoluta del estado de naturaleza, pues si así fuera no podrían actuar como "un pueblo" o "un cuerpo político", o "una comunidad" o como "individuos de una sociedad política". Es por esta razón que Locke nos dice que, cuando no se puede evitar el daño, ni disponer de la acción de la judicatura para castigar u obtener reparación o seguridad alguna, a causa de la discrecionalidad ilimitada de "aquel que hace los que le place" (alusión a la fórmula real de la monarquía absoluta de Francia, que antecedía la firma del rey en todos los documentos legales: "pour le bon plaisir du roi"), los gobernados tienen derecho a considerarlo "fuera de la sociedad civil"83. Resulta claro,

\footnotetext{
${ }^{79}$ Locke, John: Second Treatise of Government, Cap. XVIII, 202, p. 102.

${ }^{80}$ Locke, John: Second Treatise of Government, Cap. VII, 91, p. 46.

${ }^{81}$ Locke, John: Second Treatise of Government, Cap. VII, 94, pp. 47-48.

${ }^{82}$ Locke, John: Second Treatise of Government, Cap. VII, 92, p. 46.

${ }^{83}$ Locke, John: Second Treatise of Government, Cap. VII, 94, p. 46.
} 
entonces, que la sociedad civil no se disuelve cuando, ante el vacío de la ley y la justicia, aplica las leyes de la naturaleza para restaurar la consecución de su propio fin.

El príncipe absoluto está más allá y por encima de la ley, y, en consecuencia, sus gobernados carecen de las garantías que emanan de la ley y la moderación del poder político, producto de la subordinación del poder ejecutivo a la supremacía del poder legislativo. El monarca absoluto, de acuerdo a lo establecido, deja de ser un magistrado y se convierte en una persona privada. Pero, como dispone de la fuerza pública, se pone en estado de guerra contra la sociedad política sobre la cual pretende ejercer un poder sin límites, que viola el principio del cual fluye la sociedad civil: el disfrute tranquilo de la vida, la libertad y los bienes de sus miembros. Razón suficiente para "clamar al cielo" y ejercer la fuerza de la sociedad civil contra la fuerza injusta.

Ahora bien, cuando Locke trata sobre la tiranía en general, nos entrega su concepción sobre las condiciones y límites del ejercicio del derecho de resistencia. Nuestro autor propone un modelo argumental que es reconocible en el análisis de dos casos. Si un individuo es asaltado para ser robado, con peligro de su vida, tiene derecho, en legítima defensa, a darle muerte, aunque el monto comprometido en el robo fuese mínimo. Si un individuo le pide a un tercero que mientras realiza una acción (montar en su caballo), le "tenga" un monto elevado de dinero, y una vez realizada dicha acción no le devuelve el dinero, sin que medie peligro para su vida, el afectado no tiene derecho para dar muerte al ladrón. El criterio que se aplica en ambos casos es que la pérdida de la propia vida excluye una acción posterior de la justicia que repare el daño, porque la vida es irrecuperable. Así, ante la inminencia de perder la propia vida, el afectado tiene derecho a quitársela a su agresor. En cambio, en el segundo caso, dado que la víctima no corre peligro de muerte, y que puede recurrir posteriormente a la justicia y conseguir la devolución de su dinero y la reparación del daño, no tiene derecho a matar al victimario ${ }^{84}$.

El modelo conceptual que subyace a los dos casos, se refiere al derecho a la legítima defensa, que parece una doctrina más cierta que la concepción del soberano que se pone en estado de guerra contra el pueblo. En efecto, la legítima defensa es un derecho inalienable de la persona, cuyo último fundamento antropológico es la vida como "propiedad fundamental de las propiedades esenciales" del ser humano. Lo importante es que Locke sostiene una doctrina fuerte sobre los derechos de la persona. Esta concep-

${ }^{84}$ Locke, John: Second Treatise of Government, Cap. XVII, 207, p. 104. 
ción se difunde en Inglaterra recién la segunda mitad del siglo XVII. En la época estaba vigente la idea de que el ejercicio de las libertades, por parte del individuo, estaba limitado por el ejercicio de las mismas libertades de los individuos; o sea, cada cual ejercía tanta libertad como se lo permitía la competencia con los demás (el caso del ius in omnia, el "derecho a todo" de Hobbes). Los derechos de la persona son libertades inmunes a la invasión o interferencia de terceros ${ }^{85}$ y esencialmente inalienables. Locke da por supuesta esta concepción de los derechos personales, y la aplica con energía al derecho de legítima defensa y al derecho a la resistencia (como extensión del primero).

Este modelo conceptual se aplica a la tiranía en su diversidad de formas, o sea, a la corrupción de todos los regímenes, trátese de la monarquía, la aristocracia o la democracia. En efecto, si el gobernante ejerce el poder fuera de los límites establecidos por la ley, no existe una instancia a la cual apelar por el daño o la injuria que padezcan las personas. La tiranía corrompe el imperio de la ley, y, por lo mismo, no hay reglas fijas que regulen los actos de las personas, ni normas que el juez imparcial pueda aplicar. Y la fuerza pública se pone a disposición de los deseos desordenados del gobernante. Por lo tanto, la causa de esa situación, es decir, el tirano singular o plural, se declara en estado de guerra contra la sociedad políticamente organizada. Y dado que eso significa, para ella y sus miembros, la inminencia de la muerte y la imposibilidad de la apelación y la reparación, se justifica la resistencia civil ${ }^{86}$, en virtud del derecho de legítima defensa.

Obviamente, la resistencia no es la conducta que los gobernados deben seguir cada vez que creen haber sufrido una injusticia, cometida presuntamente por el gobernante, pues eso precipitaría a la sociedad civil a la anarquía y el desconcierto ${ }^{87}$. Locke dice reiteradamente que solamente debe oponerse la fuerza a la fuerza injusta e ilegal $^{88}$. O sea, a la fuerza pública aplicada por aquel o aquellos que ejercen el poder sin sujeción a la ley (ilegal) y causando daño a lo suyo de cada cual, que en esencia es su vida, su libertad y sus bienes (el autor les da la denominación general de "propiedades", properties); se entiende que se trata de propiedades de la persona ${ }^{89}$.

${ }^{85}$ Simmons, A. John: On the Edge of Anarchy, 1993; p. 152. Del mismo autor, The Lockean Theory of Rights, 1992.

${ }^{86}$ Locke, John: Second Treatise of Government, Cap. XVIII, 207, p. 104.

${ }^{87}$ Locke, John: Second Treatise of Government, Cap. XVIII, 203, p. 102.

${ }^{88}$ Locke, John: Second Treatise of Government, Cap. XVIII, 204, p. 102.

${ }^{89}$ Numerosas traducciones españolas de Locke traducen la palabra propiedad confundiéndola con posesión. Locke usa possesions, goods, estates, etc. para referirse a los bienes materiales, nunca el término property. 
Las personas que resisten la autoridad del gobernante, sin que se cumpla la condición necesaria ya expuesta, se hacen acreedores de la "justa condena de Dios y los hombres" $"$. Por esta razón, la sociedad civil no está sujeta a peligros permanentes, pues su estabilidad está asegurada por la condición expuesta. Pero, además, porque los regímenes tienen distintos recursos de protección. En primer término, hay regímenes en que la persona del gobernante es sagrada por disposiciones expresas de la ley ${ }^{91}$. En este caso, la ley pone vallas protectoras que hacen inmune al gobernante ante acusaciones, críticas, censuras o condenas judiciales. La cobertura del gobernante es máxima. En cuyo caso el gobernante sólo se pone en estado de guerra contra el pueblo cuando disuelve el parlamento. Un acto de esta naturaleza anula el imperio de la ley, y la fuerza pública del soberano solamente se puede ejercer de modo ilegal e injusto. Hay que tomar en cuenta que para Locke disolver el poder legislativo es equivalente a disolver el régimen político o anular el sistema constitucional. Sin gobierno, la comunidad política actualiza su libertad para protegerse contra el enemigo hostil, usando la fuerza y su poder constituyente para elegir un nuevo régimen político, por decisión mayoritaria.

Un aspecto importante de la teoría lockeana de la resistencia civil es que el tirano, por el mismo hecho de ponerse sobre la ley, pierde su investidura pública: deja de ser magistrado, o sea, persona pública. La desobediencia civil, que puede preceder al uso de la fuerza activa contra el tirano, materializa el hecho de que el tirano es una persona privada. Pero, en un régimen en que la persona del monarca es sagrada según la ley, y cuyo gobierno no rompa el límite establecido, la verdad es que los actos injustos que puedan sufrir de su mano algunos particulares serán siempre de inferior entidad que el mal de la anarquía. Nunca el poder "personal" de un príncipe, al interior de un sistema político moderado, es suficiente para subvertir la ley u oprimir a la totalidad del pueblo"92.

También está salvaguardado el gobernante de la resistencia civil cuando es un magistrado subalterno, que actúa en delegación suya, el que viola los límites de la ley. Aunque este magistrado disponga de un mandato, por ejemplo, del rey para actuar en contra de alguien, su autoridad no proviene del monarca sino de la ley. Y la ley no puede ser violada bajo ninguna circunstancia. No es el mandato o la delegación que le entrega el gobernante aquello que confiere autoridad, sino la ley. La responsabilidad

\footnotetext{
${ }^{90}$ Locke, John: Second Treatise of Government, Cap. XVIII, 204, p. 102.

${ }^{91}$ Locke, John: Second Treatise of Government, Cap. XVIII, 205, p. 102.

${ }^{92}$ Locke, John: Second Treatise of Government, Cap. XVIII, 205, p. 102.
} 
del exceso recae, en consecuencia, sobre el magistrado subordinado que traspasa los límites de la ley y no sobre el gobierno ${ }^{93}$.

Una tercera consideración merece el caso de los gobiernos en que la persona del primer magistrado no está protegida por la sacralidad otorgada por la ley ${ }^{94}$. La ausencia de esta inmunidad no autoriza a los individuos a ejercer el derecho de resistencia por cualquier motivo. Basta que los individuos estén bajo el imperio de la ley y tengan acceso a la justicia, para que esté vigente la prohibición de la resistencia a la autoridad del gobernante. Se aplica, en este caso, el mismo principio ya enunciado (solamente se puede emplear la fuerza contra la fuerza ilegal e injusta). Dice Locke, en esta sección, "no se puede afirmar que se es víctima de una fuerza hostil sino cuando se impide el recurso de apelación, y únicamente la fuerza que priva al perjudicado de ese remedio, coloca a quien la emplea en un estado de guerra, y da, por tanto, legalidad a "la resistencia que se le ofrezca" 95 .

Locke, en cuarto lugar, acepta la ocurrencia de actos de tiranía aislados ${ }^{96}$. Ello no constituye un designio manifiesto de gobernar en la ilegalidad, sino caer en actos de ilegalidad. Si esos actos causan daño a algunos y la resistencia de éstos no le interesa a la mayoría, es manifiesto que el gobierno prevalecerá.

Ahora bien, si los actos de injusticia afectan a la mayoría o bien a una minoría, pero, por su naturaleza, tienen el efecto de constituir un precedente para nuevos casos, la situación es distinta. Se supone que estos actos causan el "convencimiento en las conciencias" de que las leyes y las propiedades de las personas corren peligro ${ }^{97}$. Tal convencimiento puede no corresponder a la realidad, pero tiene un efecto que fácilmente un buen gobernante puede evitar. En este contexto, Locke incluye la consideración de una cuestión álgida en su época: la religión. Y el texto nos entrega una novedosa percepción del poder de la opinión pública. No se trata por lo tanto del sistemático quebrantamiento tiránico de la ley, que tiene el efecto de corromper la naturaleza de un régimen político, sino del sentimiento y convencimiento popular de que el gobierno actúa dañando bienes fundamentales de la comunidad, como la religión. Locke le atribuye a la comunidad (el pueblo) la capacidad para interpretar los actos del gobierno y leer en ellos la posibilidad de un designio adverso a sus fines y al bien común, tal como ella lo estime. Así, podría ocurrir que actos aparentemente normales del gobierno, como la designación de magistrados, ministros, jueces u

\footnotetext{
${ }^{93}$ Locke, John: Second Treatise of Government, Cap. XVIII, 206, p. 103.

${ }^{94}$ Locke, John: Second Treatise of Government, Cap. XVIII, 207, p. 103.

${ }^{95}$ Locke, John: Second Treatise of Government, Cap. XVIII, 207, p. 104.

${ }^{96}$ Locke, John: Second Treatise of Government, Cap. XVIII, 208, p. 104.

${ }^{97}$ Locke, John: Second Treatise of Government, Cap. XVIII, 209, pp. 104-105.
} 
otros, revelen un propósito contrario a los intereses de la comunidad política, ante los cuales se debe actuar preventivamente. Obviamente Locke se está refiriendo a la monarquía de los últimos Estuardo (Carlos II y Jacobo II). Y, en este sentido, el texto refleja el estado de la política inglesa de su época. Por esta razón, el texto produce algo de perplejidad, porque no queda claro si las presunciones de tiranía son suficientes para desencadenar la resistencia civil.

\section{Conclusión}

Locke se instala en la teoría política moderna ofreciendo una visión tradicional de la libertad natural de la persona humana, a la cual le da una proyección política totalmente nueva como fundamento de la commonwealth y del poder político. Si comparamos a Locke con los autores mencionados en la primera parte de este ensayo, descubrimos grandes afinidades en todo aquello que concierne al origen del poder político y a la libertad, igualdad e independencia naturales del hombre. Sin embargo, las diferencias son sustantivas, pues ninguno de ellos logra establecer las bases de una sociedad civil en que la libertad y el consentimiento de los individuos y la comunidad política operen como una causalidad continua de la vida y actividad del régimen político. En Locke no hay, como en Grocio y Pufendorf, una alienación del gobierno de sí mismo para transferirlo a un tercero, el soberano. Locke es el primero en sustentar que los individuos transfieren parte de sus derechos naturales - el de castigar al que viola la ley natural, por ejemplo - no a un soberano singular o plural, sino a la sociedad civil o política a la cual se integran; y también el primero en depositar en ella la facultad de constituir al régimen político por decisión mayoritaria y confiriéndole un poder delegado que nuestro autor llama fiduciario. O sea, un poder esencialmente revocable, sujeto a la condición necesaria de que el fideicomisario (trustee), o sea el régimen y el gobierno, cumpla con la finalidad del fideicomiso (trust), que le ha encomendado el pueblo $^{98}$. Ésta es la plataforma contra la tiranía. Para Locke el poder político "decente" y legítimo es aquel que está sometido al escrutinio de los gobernados, que en última instancia disponen del derecho de resistencia. La sujeción política que fluye de los postulados de Locke no es obediencia pasiva, como propone el absolutismo, sino la participación activa en el establecimiento de la ley y el parlamento y en la guarda y protección de los fines de la comunidad civil.

${ }^{98}$ Godoy, Óscar: "Libertad y Consentimiento en el Pensamiento Político de John Locke", 2004. 
El derecho de resistencia se aplica de manera distinta, aunque sus efectos son los mismos, cuando se trata de la monarquía absoluta que en el caso de la tiranía. La monarquía absoluta es un "no" régimen, como diría Platón. En consecuencia, su titular es por definición "un" individuo que se exceptúa del ingreso al cuerpo político y que se vale de los procedimientos del estado natural de guerra para someter al cuerpo político a su singular y total dominación. En cambio, la tiranía es siempre, para Locke, la corrupción de un régimen político legítimamente establecido —originado en un contrato expreso-, cuyo gobernante viola los fines de la sociedad civil o política y gobierna por encima de la ley y del poder legislativo. Locke está plenamente consciente que el derecho a la resistencia es un derecho a la revolución. Y que la revolución es un plano inclinado a la anarquía, que es la peor enfermedad que puede experimentar una comunidad política. Tal conciencia explica las limitaciones y condiciones que establece para el ejercicio de este derecho, que se funda en la salvaguardia de la vida, la libertad y las posesiones de las personas. Y la anarquía, justamente, tal como la tiranía, pone en vilo ese supremo fin.

\section{REFERENCIAS BIBLIOGRÁFICAS}

Ashcraft, Richard: Revolutionary Politics and Locke's Two Treatises of Government. Princeton University Press, 1986.

Bossuet, Jacques-Bénigne: Politique Tirée des Paroles de la Ecriture Sainte. Ginebra: Librairie Droz, 1967.

Cranston, Maurice: John Locke: A Biography. Oxford: Oxford University Press, 1985.

Dunn, John: The Political Thought of John Locke. Cambridge, London, New York: Cambridge University Press, 1969.

Filmer, Robert: Patriarca o el Poder Natural de los Reyes. Madrid: Instituto de Estudios Políticos, 1966.

Godoy, Óscar: "Libertad y Consentimiento en el Pensamiento Político de John Locke". En Revista de Ciencia Política, Vol. XXIV, No 2, Santiago, P. Universidad Católica de Chile, 2004.

Grocio, Hugo: El Derecho de la Guerra y la Paz. Madrid: Editorial Reus, 1925.

Hobbes, Thomas: Leviatán. México: Fondo de Cultura Económica, 2003.

Hobbes, Thomas: De Cive. Madrid: C.S.I.C. y Editorial Debate, S.A., 1993.

King James VI and I: Political Writings. Cambridge: Cambridge University Press, 1994.

Laslett, Peter (ed.): John Locke: Two Treatises on Government. Cambridge: Cambridge University Press, 1967.

Locke, John: Le Magistrat Civil (An Magistratus Civilis posi res adphoras in divini cultus ritus asciescere, eosque populo imponere? Afirmo). René Fréreux, editor. Centre de Philosophie Politique et Juridique de l'Université de Caen, 1984.

Locke, John: Two Tracts on Government. Philip Abrams, editor. Cambridge: Cambridge University Press, 1967. 
Locke, John: Primer Tratado sobre el Gobierno. Madrid: Instituto de Estudios Políticos, 1966.

Locke, John: Second Treatise of Government. Oxford: Blackwell and Basil, 1976.

Marsilio de Padua: El Defensor de la Paz. En Godoy, Óscar: "Antología del Defensor de la Paz de Marsilio de Padua". En Estudios Públicos, N 90, otoño, 2003.

Milton, J. R.: "Locke's Life and Times". En Vere Chapell (ed.), The Cambridge Companion to Locke. Cambridge: Cambridge University Press, 1994.

Pufendorf, Samuel: Le Droit de Nature et des Gens [Edition de Bâle, 1732]. Centre de Philosophie Politique et Juridique, Université de Caen, 1987.

Simmons, A. John: The Lockean Theory of Rights. Princeton, New Jersey: Princeton University Press, 1992.

Simmons, A. John: On the Edge of Anarchy. Princeton, New Jersey: Princeton University Press, 1993.

Suárez, Francisco: Tractatus de Legubus ac Deo Legislatore. Madrid: Consejo Superior de Investigaciones Científicas, Instituto Francisco de Vitoria, 1977.

Tomás de Aquino. Suma de Teología, Vol. II. Madrid: Biblioteca de Autores Cristianos, 1993.

Tully, James: Approach to Political Philosophy: Locke in Contexts. Cambridge: Cambridge University Press, 1993. 